\title{
Different routes to regionalization
}

Previously published at www.cmaj.ca

Y ou could think of Canada's regional health authorities as a fleet of cars: They vary in size, they vary in power and you can't tell what they're really made of until you pop the hood and take a look inside. Except for Alberta and Prince Edward Island, which have abandoned regional models, all provinces use some variant of regionalization. But how the regional model is implemented varies widely. Some experts say this is to be expected, as the health care needs of provinces also vary widely, but note that the lack of uniformity makes it difficult to answer a much-debated question: Has the regionalization of health care in Canada been successful?

"Regionalization, as a whole, has been hard to evaluate as a system because it was implemented in so many different ways," says Denise Kouri, who from 2002 to 2005 directed the nowdefunct Canadian Centre for Analysis of Regionalization and Health, which was based in Saskatoon, Saskatchewan.

Some regional health authorities serve populations of less than 10000 , while others serve more than a million people. "What is the right size? That was always a big debate, especially in a place like Saskatchewan, which has a low population density," says Kouri. "You end up having big geographical regions, which in some ways defeats the purpose of regionalization."

How much effort should be put into involving citizens in health care decisionmaking is another hot topic. Advocates of regionalization pitched community engagement as a primary selling point of dividing health care systems into regions. A few health regions have tried elected boards as a means of providing public accountability, though the vast majority of board members in the nation's health regions are appointed. In a 2006 scan of the effects of regionalization on community health centres, the Association of Ontario Health Centres found that provinces were inconsistent in their commitments to community engagement (www.aohc.org/app/wa/doc?docId=164).

"Effective community engagement strategies are not consistently applied

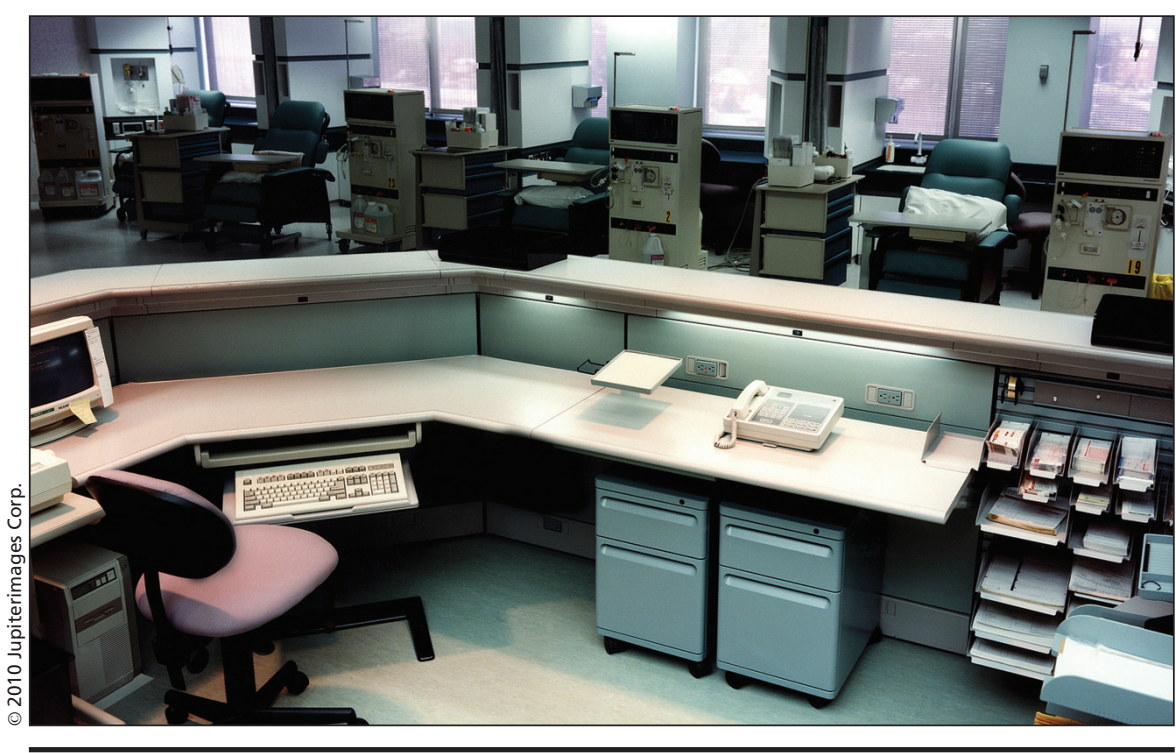

The lights have gone out for good in many rural hospitals because of regionalization, says Dr. Karl Stobbe, president of the Society of Rural Physicians of Canada, who describes regionalization as "a euphemism for rural hospital closures."

across all health regions (even within a province). Support for meaningful engagement is largely determined by the beliefs, values and commitment of health authority decision makers," the report states.

The range of services also depends upon location. A 1997 analysis conducted by researchers at McMaster University in Hamilton, Ontario, found that the scope of services varied significantly across the country (CMAJ 1997;156:371-7). New Brunswick, for instance, had implemented a system that granted health regions only the power to control institutions, such as hospitals and nursing homes. Other provinces, such as Manitoba and British Columbia, created regions that were in charge of institutions plus such services as home care and public health. And Prince Edward Island, during that time, had a regional system that included social services.

"The variable scope of services in each province partly reflects the differences in the main objectives of each provincial government," the paper states. "The narrower the scope of services, the more likely it is that the principle objective of the reform was to improve efficiency (and therefore reduce expenditures) or to increase integration and coordination. ... The broader the scope of services, the more likely it is that the province was concerned with broad population health."

Because the degree of autonomy varied from province to province, certain regional health authorities, as they evolved, developed stronger political voices than others. According to some health care experts, Alberta, before abandoning regionalization in 2008 , had the most powerful regional health authorities in Canada. The leaders of Alberta's health regions had developed such strong voices politically, some observers suggest, that the province dissolved the regions to quiet them down.

"Alberta was basically seen as the poster boy for regionalization," says John Church, an associate professor in the School of Public Health at the University of Alberta in Edmonton.

One reason provinces implemented regionalization differently, according to some health care experts, is that no single system would work for each province. "If we truly believe in needsbased planning, how can we say that one model is going to fit across the country?" says Pamela Fralick, president and chief executive officer of the Canadian Healthcare Association. "Every province has to look at its needs." 
Though there are many differences between health regions, there is some common ground. Most regional health authorities have appointed boards and are granted global budgets by their provincial governments. They also all lack control over two significant health care expenditures: physicians' fees and drugs. Another commonality, at least according to rural physicians, is that regional health authorities have not been kind to smaller communities.

For small communities, regionaliza- tion has, in effect, been centralization. In efforts to improve efficiency by reducing the duplication of services in areas of low population density, some regional boards have closed rural hospitals or have closed particular departments of regional hospitals. According to some doctors, the money saved might be coming at the cost of human lives. For instance, Ontario Ombudsman André Marin is investigating a regional health agency in the Niagara region after receiving numerous com- plaints that two emergency rooms in the area were closed without proper public consultation.

"It's not that we are against regionalization; it's just how it has been implemented in almost every region in Canada," says Dr. Karl Stobbe, president of the Society of Rural Physicians of Canada, who describes regionalization as "a euphemism for rural hospital closures." - Roger Collier, CMAJ

DOI:10.1503/cmaj.109-3166

\section{Is regionalization working?}

Previously published at www.cmaj.ca

$\mathrm{F}$ or more than a decade, the dominant model of health care in Canada has been regionalization, but health care experts still aren't sure if the national shift toward delivering medical services at the regional level has been successful. In the 1990s, when many provinces were implementing regional systems, advocates of regionalization were fond of tossing out grand-sounding promises: greater accountability, increased citizen participation in decision-making, better integration of services. Some of those promises were realized, experts say, while others turned out to be nothing more than unfulfilled optimism.

One phrase that comes up often in talks about regionalization is "from silos to systems." This refers to the shifting of service provision and decision-making power from local entities to larger, regional bodies which, the theory goes, can more effectively and efficiently deliver health care services. In the late 1990s, John Church, an associate professor in the School of Public Health at the University of Alberta in Edmonton, turned a critical eye toward regionalization in Canada and cast doubt on this theory.

"At a minimum, regionalization arrangements have to recognize that, given the varied nature of services, it is inadvisable to assume that cost savings and improved quality will flow from consolidation efforts," Church wrote in a 1998 paper (Int J Health Serv 1998;

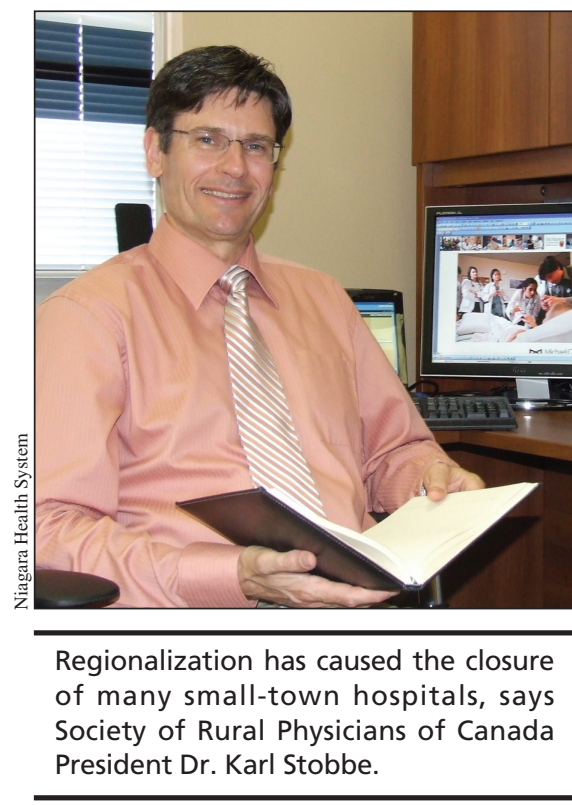

28:467-86). "All in all, regional populations in Canada might be too small to achieve any real economies of scale or to more generally effect a coordination of health services."

But as regional health authorities matured, Church says, they began to show more promise. For instance, regionalization has proven beneficial in areas where physicians need to keep busy to maintain important skills, such as surgical skills.

"Everybody who needed surgery would go to a smaller number of outlets and keep cardiovascular surgeons busy and not sitting around having their skills wax and wane," says Church.

One area where regionalization has failed, though, is in increasing citizen participation in health care decisionmaking. Engaging the public, of course, is not always easy. In his paper, Church cites the work of another researcher who looked at efforts to empower communities in the United Kingdom, Sweden and the United States but found: "In analysis of these three countries, one finding repeatedly emerged: no matter the organization arrangements or modes of financing, professionals dominated decisionmaking in the health sector." (Comp Politics 1985;17:399-420)

"Community participation is one part that never got off the ground, but governments weren't interested in that," says Church. "In fact, they were probably seriously interested in moving away from that model."

Another promise of regionalization was health care equity across provinces. Critics of regionalization, however, claim that the exact opposition may have happened - urban centres have gained more power while rural areas have lost power.

According to Dr. Karl Stobbe, president of the Society of Rural Physicians of Canada, regionalization has caused the closure of many smalltown hospitals. As a result, rural people - who "still get sick and injured whether there is a hospital or not" have lost their voice.

"Decision-making power almost always rests in urban centres," says Stobbe. "Our notion is that more than just the bottom lines of urban hospitals need to be looked at." 